\title{
Speed control of DC motor using conventional and adaptive PID controllers
}

\author{
Sarah N. Al-Bargothi ${ }^{1}$, Ghazi M. Qaryouti ${ }^{2}$, Qazem M. Jaber ${ }^{3}$ \\ ${ }^{1}$ Department of Mechatronics Engineering/ Faculty of Engineering, Hashemite University, Jordan \\ ${ }^{2,3}$ Department of Mechatronics Engineering/ Faculty of Engineering Technology, \\ Al Balqa' Applied University, Jordan
}

\begin{tabular}{l} 
Article Info \\
\hline Article history: \\
Received Jan 26, 2019 \\
Revised May 5, 2019 \\
Accepted Jun 17, 2019 \\
\hline
\end{tabular}

Keywords:

Adaptive PID (APID) controller recursive least square (RLS)

DC motor

PID controllers

\begin{abstract}
Proportional Integral Derivative (PID) controllers are extensively used in practical industries to control the speed of DC Motors. The single weakness of PID controllers is their sensitivity to variation in parameters and operating conditions; thus, tuning the controller gains to adapt with these variations presents a practical challenge. In this paper, an adaptive mechanism that utilizes a Recursive Least Square (RLS) algorithm, with rate limiters, is implemented to perform an online self-adjusting of each of the PID gains in order to achieve Adaptive PID (APID) controller that will accommodate to system variations. MATLAB/ Simulink software is used to implement and simulate APID control of a Chopper-Fed DC motor. A conventional PID control system is also designed and simulated to obtain results that can be used to judge the performance of the APID controller. Results proved that the APID controller forced the motor speed to track the reference input with insignificant tracking error, and also managed to attain the motor speed at its desired value, regardless of the load changes inflected on the motor. This enhances both transient and steady-state speed responses.
\end{abstract}

Copyright @ 2019 Institute of Advanced Engineering and Science. All rights reserved.

Corresponding Author:

Ghazi M. Qaryouti, Department of Mechatronics Engineering, Faculty of Engineering Technology.

Al Balqa’ Applied University, Amman, Jordan.

Email: ghazi_qaryouti@bau.edu.jo

\section{INTRODUCTION}

Many applications use dc motor to benefit from their simple, wide and precise control characteristics. Such applications include, for example robotic manipulators, steel rolling mills, electric trains, cranes, electric cars, etc [1-2]. Even the Brushless DC (BLDC) motor has been developed with higher efficiency in operation than classic DC motor [3]. The most flexible control is obtained by means of Separately Excited DC Motor (SEDM). The best quality of this motor is that it provides high torque load sustainable property, and it can be used with batteries and solar cells [4]. DC motors are a good field to study advanced control algorithms, due to the fact that its theory can be projected on other types of motors [5].

The speed control of dc motor with power electronic systems is obtained generally by changing its terminal voltage. A PID controller is a good candidate for speed control of dc motors. It is the most common controller used in industry due to its simplicity and ease of implementation [6]. In addition, the PID controller is used for controlling the brushless dc motor by designing two controller types Fuzzy logic and PI controllers [7]. The unknown dc motor parameters could be estimated by experimental data onto armature current and speed response, or by adapting an adaptive model with reference model created based on experimental data [8]. In some cases the system parameters are changing during operation, and the PID controller cannot adjust its own gains to cope with these changes, which will emanate the need to online retune the PID gains, aka adaptive PID [9]. Parameters tuning of the dc motor has been used by different 
procedure as an example Fractional Order Proportional Integral Derivative [10]. An adaptive controller for a dc motor is also designed by utilizing Lyapunov-like function methods based on Digital Signal Processing platform [11].

Proportional Integral Derivative (PID) controllers acquire more than $95 \%$ of the controllers in the industrial process control applications; this is accredited to their robust performance, ease of implementation, and functional simplicity. The major flaw of the PID controller is its high sensitivity to variation in the motor parameters and load disturbance. Another disadvantage of such controller is that, it is difficult to tune PID gains $[4,6]$.

Adaptive control techniques can be employed to overcome these deficiencies of conventional PID controller. Adaptive Proportional Integral Derivative (APID) control provides fast speed response and parameter insensitivity [12]. An adaptation mechanism is combined with the conventional PID control to auto-tune the controller gain during system operation. The adaptation mechanism adopted in this thesis is Recursive Least Square (RLS) adaptation algorithm.

\section{SEPARATELY EXCITED DC MOTOR AND DRIVE}

Voltage controlled speed controller of dc motors was introduced for the first time by Ward Leonard in 1981 [13] and the field has witnessed a great advancement since. Choppers are used to obtain a controlled dc voltage from a fixed dc source. The speed of the separately excited DC motor can be controlled by the armature voltage, $V_{a}$, known as voltage control.

\subsection{Separately Excited DC Motor (SEDM)}

The equivalent circuit of the motor is presented in Figure 1 [14]. Armature and field winding are supplied separately, which makes $i_{f}$ independent of $i_{a}$. The interaction of field flux and armature current in the rotor produces torque [4]. When a SEDM is exhilarated by a field current and armature current $i_{f}$ and $i_{a}$, the motor induces a back emf and a torque to balance the load torque at a particular speed. Motor parameters and calculations are shown in Tables 1 and 2.

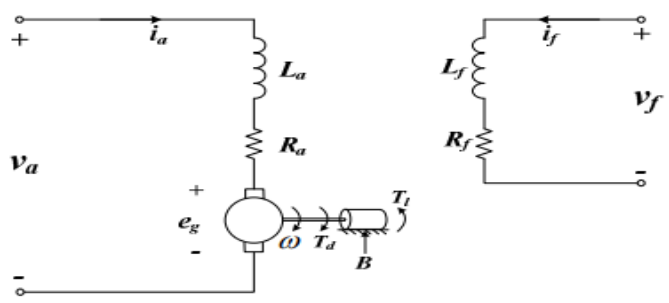

Figure 1. Equivalent Circuit Diagram of SEDM

Table.1 Motor Parameters

\begin{tabular}{ccc}
\hline Parameter & Value & Unit \\
\hline Ra & 0.78 & $\Omega$ \\
La & 0.016 & $\mathrm{H}$ \\
Rf & 150 & $\Omega$ \\
Lf & 112.5 & $\mathrm{H}$ \\
Laf & 1.234 & $\mathrm{H}$ \\
Bm & 0.01 & N.m.s \\
$\mathrm{J}$ & 0.05 & kg.m ${ }^{2}$ \\
\hline
\end{tabular}

Table 2. Motor Calculated Parameters

\begin{tabular}{ccc}
\hline Parameter & Value & Unit \\
\hline $\mathrm{I}_{\mathrm{a} \_ \text {rated }}$ & 13.66 & $\mathrm{~A}$ \\
$\mathrm{I}_{\mathrm{a} \_ \text {start }}$ & 307.69 & $\mathrm{~A}$ \\
$\mathrm{I}_{\mathrm{f} \text { rated }}$ & 1 & $\mathrm{~A}$ \\
$\mathrm{~T}_{\mathrm{e} \_ \text {rated }}$ & 20.37 & $\mathrm{~N} . \mathrm{m}$ \\
$\mathrm{k}_{\mathrm{t}}$ & 1.2341 .234 & $\mathrm{~N} . \mathrm{m} / \mathrm{A}$ \\
$\mathrm{k}_{\mathrm{b}}$ & & V.s $/ \mathrm{rad}$ \\
\hline
\end{tabular}


The back electromotive force $e_{a}$ is proportional to the motor speed, and the electromagnetic torque developed in the motor is proportional to the armature current as presented by (1) and (2).

$$
\begin{gathered}
e_{a}=k_{b} \omega \\
T_{e}=k_{t} i_{a}
\end{gathered}
$$

Applying Kirchhoff's Voltage Law (KVL) to the armature circuit:

$v_{a}=i_{a} R_{a}+L_{a} \frac{d i_{a}}{d t}+e_{a}$

Applying Newton's second law to the mechanical shaft:

$J \frac{d \omega}{d t}=T_{e}-T_{L}-B_{m} \omega-T_{f}$

Rearranging equations the previous equations and taking the Laplace transformation will yield to the SEDM block diagram shown in Figure 2.

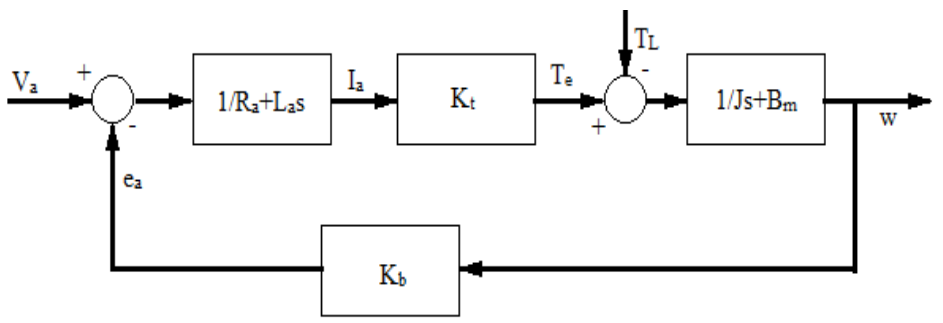

Figure 2. Block Diagram of SEDM

\subsection{Chopper Drive of DC Motors}

Chopper is a static power electronic device. It acts as a high speed on/off switch; that connects or disconnects the load from the dc source $V_{i n}$, which creates a chopped dc voltage at the load terminal $V_{a}$. Chopper drives are widely used in speed control of SEDM, and can achieve speed ranges above or below the rated speed of the motor. In this thesis buck chopper as illustrated in the circuit of Figure 3 [15] is used to control the motor terminal voltage $V_{a}$.

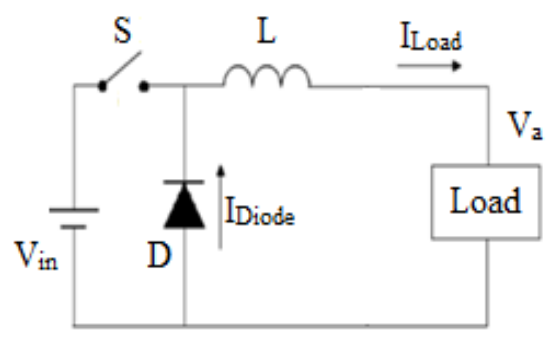

Figure3. Schematic Circuit of Class A Buck Chopper

The chopper DC voltage transfer function, defined as the ratio of the output voltage to the input voltage, is:

$\frac{V_{\text {in }}}{V_{a}}=D$

This ratio D is called the Duty Cycle of the chopper. 


\section{CONTROLLER DESIGN}

PID controllers are the most commonly used controller in industrial practice for more than 60 years [6], they compose $90 \%$ of controllers on process control fields [16]. A conventional closed loop PID control system block diagram is illustrated by Figure 4 .

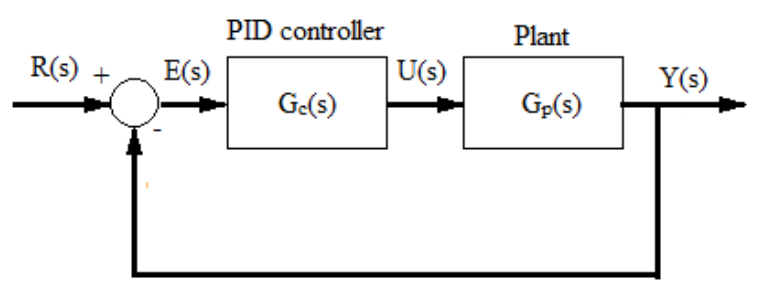

Figure 4. Closed Loop PID Control System Block Diagram

As shown in (6) represents a PID controller where $k_{p}, k_{I}$ and $k_{d}$ are the controller gains, $\mathrm{U}(\mathrm{s})$ and $E(s)$ are the control signal and error signal, respectively.

$$
U(s)=\left(k_{p}+\frac{k_{i}}{s}+k_{d} s\right) E(s)
$$

With all its praises, conventional PID controllers have some defects such as the difficulty of tuning the controller gains, and the poor self-adaptability, both of which justifies the need of adaptive control [17]. The difference between a conventional controller and an adaptive controller is that the parameters of the later, noted as $\theta$, are time variant.

Model reference adaptive control (MRAD) has been a well-developed approach of the adaptive control [17] (Tao 2003). Its objective is to force the plant to track the response of some given reference model $[18,6]$. A MRAC controller block diagram is presented in Figure 5, it consists of a reference model $\mathrm{G}_{\mathrm{m}}$, a controller, and an adaptive mechanism. An error is generated whenever the actual output of the system fails to track the reference model output, this error is called the tracking error et, and it is the difference between the actual output of the system $y(t)$ and reference model output $y_{m}(t)$ :

$$
e_{t}(t)=y(t)-y_{m}(t)
$$

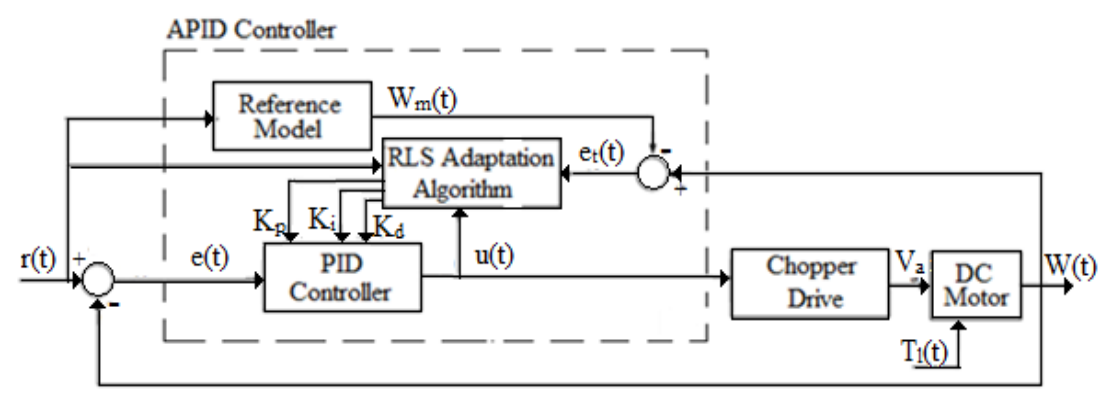

Figure 5. MRAC with PID Control Law of Chopper-Fed DC Motor Schematic Diagram

The adaptation mechanism provide the controller with parameters $\theta(t)$ at each sampling time, depending on the values of $\mathrm{te}_{\mathrm{t}}(\mathrm{t}), \mathrm{u}(\mathrm{t})$, and desired input $\mathrm{r}(\mathrm{t})$. The purpose of the Adaptive algorithm is to find the controller gains such that $e_{t} \approx 0$. According to [5] the output $y(t)$ is almost equal to the reference model output $y_{m}(t)$, that is:

$$
y_{m}(t) \approx y(t)
$$

Which is rewritten as: 


$$
G_{m}(s) r(t) \approx r(t)-e(t)
$$

The main purpose of this algorithm is to estimate the new parameters vector $\theta\left(t_{k}\right)$ at time instant $t_{k}$ by adding a correction vector to the previous parameters estimation vector $\theta\left(t_{k-1}\right)$ at time instant $t_{k-1}$ [19]. The estimation error in (9) is to be minimized using RLS algorithm, It, recursively and online, estimates $\theta(t)$ by applying the following equations [5]:

$$
\begin{aligned}
& K\left(t_{k}\right)=P\left(t_{k-1}\right) \varphi\left(t_{k}\right) \times\left[I+\varphi^{T}\left(t_{k}\right) P\left(t_{k-1}\right) \varphi\left(t_{k}\right)\right]^{-1} \\
& P\left(t_{k}\right)=P\left(t_{k-1}\right)-K\left(t_{k}\right) \varphi^{T}\left(t_{k}\right) P\left(t_{k-1}\right) \\
& \theta\left(t_{k}\right)=\theta\left(t_{k-1}\right)+K\left(t_{k}\right)\left[u\left(t_{k}\right)-\varphi^{T}\left(t_{k}\right) \theta\left(t_{k-1}\right)\right]
\end{aligned}
$$

Where $K(t)$ is the adaptation gain and $P(t)$ is the covariant matrix, which is a 3 by 3 matrix given as:

$$
P(t)=\alpha I
$$

And $\alpha$ is the learning rate of the algorithm.

\section{SIMULATION THE CONTROL SYSTEM USING MATALB/ SIMULINK AND RESULTS}

In this paper work an APID controller is designed and simulated to control the speed of a chopperfed dc motor when the motor load is varied according to a fan load. In order to have a better judgment of the system performance, the motor with the same loading condition will be controlled with conventional PID controller. Both PID and APID speed control system are modeled using MATLAB/Simulink as presented in Figures 6 and 7 respectively.

The MATLAB/Simulink models consist of the following blocks:

a. Chopper-Fed Separately excited dc motor;

b. PID controller;

c. Reference model;

d. RLS adaptation algorithm

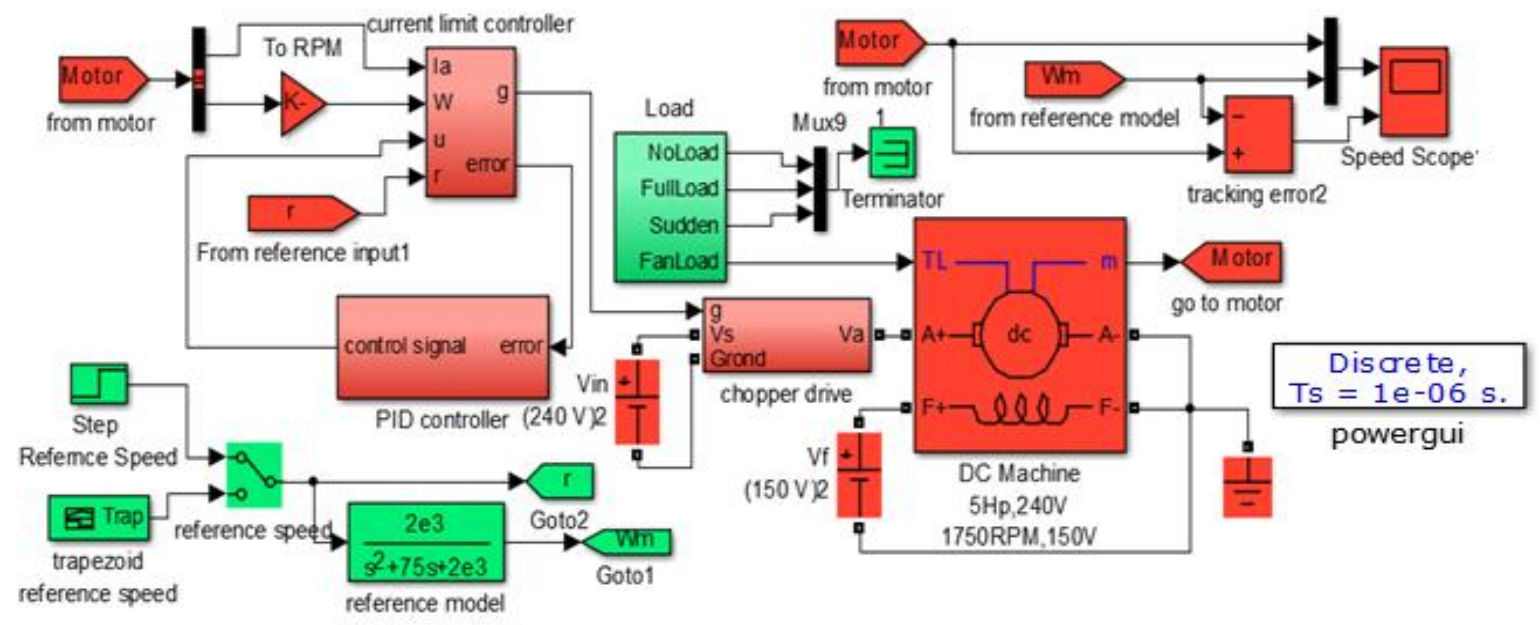

Figure 6. MATLAB/Simulink Model of Closed Loop PID Control of Chopper-Fed DC Motor

The motor is subjected to a step input of amplitude $1750 \mathrm{rpm}$ with a load that is proportional to the square of the motor speed. The speed responses of the motor are illustrated in Figure 8. 


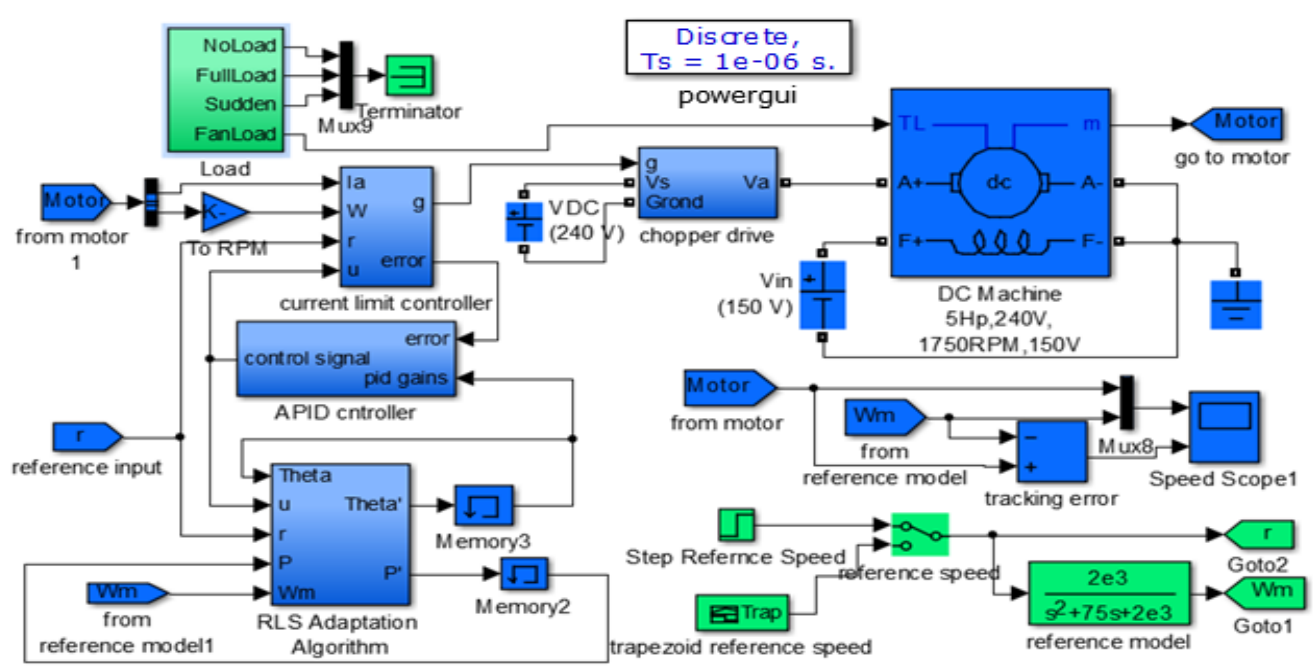

Figure 7. MATLAB/Simulink Model of APID Control of Chopper-Fed DC Motor

The similarity of the APID control system speed and the reference model's is very obvious at first sight. The APID controller achieves excellent tracking, with only $e_{t}$ of $27.9362 \mathrm{rpm}$. The PID controller, on the other hand had a higher $e_{t}$ of $40.7299 \mathrm{rpm}$, the superiority of the APID controller tracking is illustrated by Figure 9 .

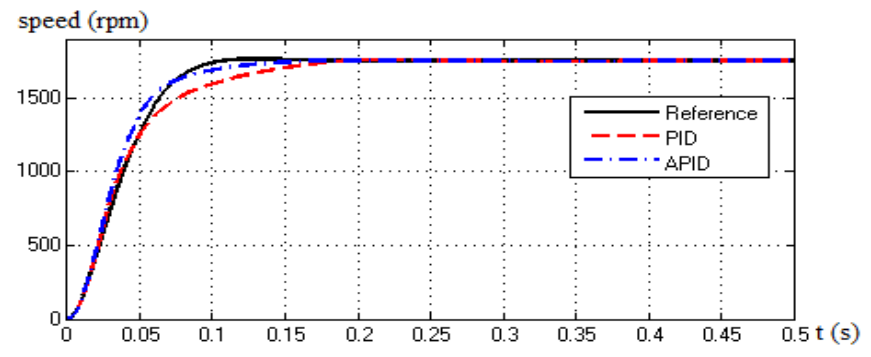

Figure 8. Speed Responses with Fan-Load

The similarity of the APID control system speed and the reference model's is very obvious at first sight. The APID controller achieves excellent tracking, with only $e_{t}$ of $27.9362 \mathrm{rpm}$. The PID controller, on the other hand had a higher $e_{t}$ of $40.7299 \mathrm{rpm}$, the superiority of the APID controller tracking is illustrated by Figure 9 .

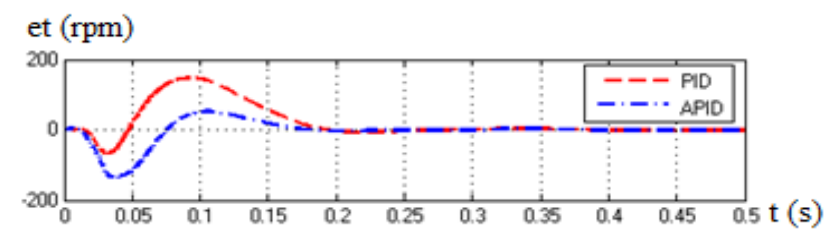

Figure 9. Tracking Error

Table 3 presents both control systems response criteria as well as that of the reference model. The APID scheme outperforms the PID scheme in every aspect. It accomplished the fastest rise and settling times, the smallest tracking and steady state errors, and a negligible percentage overshoot. The percentage overshoot of the APID controller is drastically reduced; it is even within the tolerated $\mathrm{e}_{\mathrm{ss}}$. 
Table 3. Comparison of Different Systems with Fan-Load

\begin{tabular}{cccc}
\hline Time response criteria & \multicolumn{3}{c}{ Control Configuration } \\
\cline { 2 - 4 }$T_{r}(\mathrm{~s})$ & Reference Model & PID Control & APID control \\
$T_{s}(\mathrm{~s})$ & 0.0586 & 0.0817 & 0.0555 \\
$P O \%$ & 0.0913 & 0.1577 & 0.1174 \\
$e_{s s}(\mathrm{rpm})$ & 0.7948 & 0.4034 & 0.2048 \\
$e_{t}(\mathrm{rms})$ & 0 & 0.4697 & 0.4697 \\
& --- & 40.7299 & 27.9362 \\
\hline
\end{tabular}

This improvement in performance is due to the fact that the APID controller gains, unlike the PID controller gains, are not constant, but they change according to the RLS adaptation algorithm to achieve perfect tracking of the reference model. The change in the adaptive controller gain is captured in Figure 10. It is clear the controller gains differ from their initial values, each to reach a value that best suit the application.
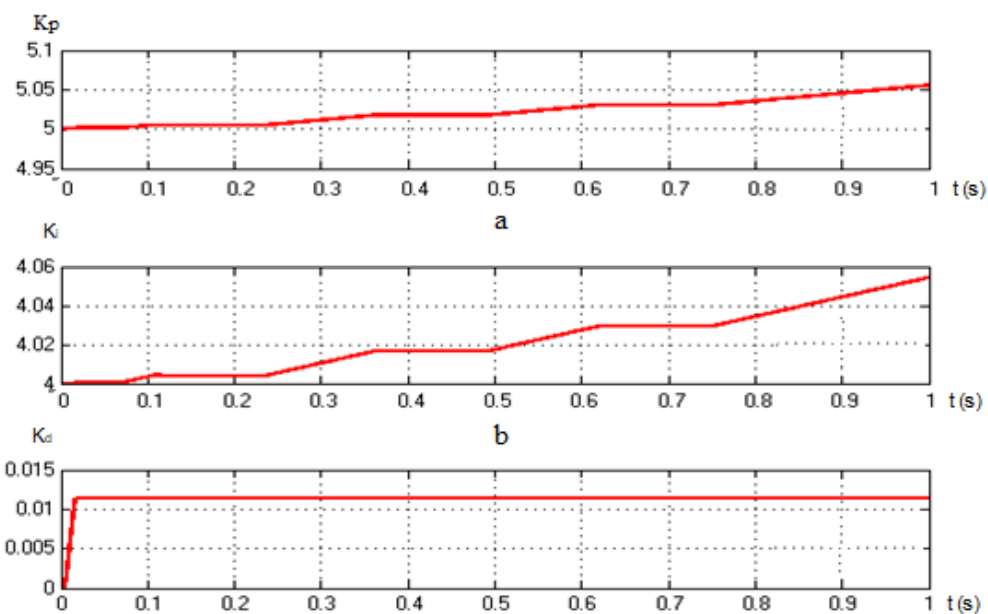

Figure 10. APID Controller Gains of Chopper-Fed Motor System with Fan-load

\section{CONCLUSION}

In this paper a model reference APID controller was designed to control the speed of chopper-fed SEDM, a RLS algorithm with rate limiters was implemented that separately adjust each of the controller gains. The APID control performance was outstanding. It kept the $P O \%$ of the transient response less than $0.2048 \%$, it accomplished fast settling of no more than $0.1577 \mathrm{~s}$, and kept the final value of the speed within $4 \mathrm{rpm}$ off the desired reference speed. Its ability of tracking the reference speed was phenomenal.

The adaptation algorithm played a key role in the performance of the controller. The RLS algorithm updated the values of the controller gain at each time instant, which allowed the controller to adopt different values of PID gains that adapted the system to changes in the load. It is an online tuning of the controller more or less, and with a rate limiter at the output of each controller gain, the rate of change in the controller gains was limited to prevent any sudden change in the controller gains which ensured system stability.

Based on the result of the work of this paper, the APID controller proved its superiority over the conventional PID controlled systems. The PID controller whilst may perform well enough under constant loading conditions, did not accomplish as good tracking in the case of variable load as did the APID controller.

\section{REFERENCES}

[1] George, M. (2008). "Speed control of separately excited DC motor." American journal of applied sciences, 5(3), 227-233.

[2] Pavankumar, S., Krishnaveni, S., Ven, gopal, Y. B., \& Babu, Y. K. (2010, November). “A neuro-fuzzy based speed control of separately excited DC motor." In Computational Intelligence and Communication Networks (CICN), 2010 International Conference on pp. 93-98. IEEE.

[3] G. G. Raja Sekhar, \& Basavaraja Banakar, "Solar PV fed non-isolated DC-DC converter for BLDC motor drive with speed control” Indonesian Journal of Electrical Engineering and Computer Science (IJEECS), Vol. 13, No. 1, 
pp. 313-323, January 2019.

[4] Khanke, M. P., \& Jain, A. P. S. (2015). "Speed control of Separately Excited DC Motor using various Conventional Controllers". International Journal of Engineering Research and Applications, 5(4), 67-72.

[5] Qadir, A. S. (2013). "Electro-mechanical modeling of SEDM (separately excited DC motor) \& performance improvement using different industrial controllers". Lulu. com.

[6] Fahmy, R. A., Badr, R. I., \& Rahman, F. A. (2014). "Adaptive PID controller using RLS for SISO stable and unstable systems". Advances in Power Electronics, 2014.

[7] Muhammed A.Ibrahim, et al. "Optimal PID controller of a brushless DC motor using genetic algorithm" International Journal of Power Electronics and Drive System (IJPEDS), Vol. 10, No. 2, pp. 822-830, June 2019.

[8] Byamakesh Nayak, , \& Sangeeta Sahu, "Parameter estimation of DC motor through whale optimization algorithm" International Journal of Power Electronics and Drive System (IJPEDS), Vol. 10, No. 1, pp. 83-92, March 2019.

[9] Mansour, T., Konno, A., \& Uchiyama, M. (2011). "Neural Network Based Tuning Algorithm for MPID Control." In PID Control, Implementation and Tuning. InTech.

[10] Badriyah Ahmed Obaid1, et al. "Resolving of optimal fractional PID controller for DC motor drive based on antiwindup by invasive weed optimization technique", Indonesian Journal of Electrical Engineering and Computer Science (IJEECS), Vol. 15, No. 1, pp. 95-103, July 2019.

[11] Alejandro. Rinc'on, et al. "Controlling a DC Motor through Lypaunov-like Functions and SAB Technique", International Journal of Electrical and Computer Engineering (IJECE), Vol. 8, No. 4, pp. 2180-2198, August 2018.

[12] Hameed, W. I., \& Mohamad, K. A. (2012). "Speed control of separately excited dc motor using fuzzy neural model reference controller." International Journal of Instrumentation and Control Systems (IJICS) Vol, 2, 27-39.

[13] Chan, C.C. (1987), Low-cost electronic-controlled variable-speed reluctance motors. IEEE transactions on industrial electronics, (1), 95-100.

[14] Sattigeri, S., Patil, M., Huded, S., and Malashetti, M., (2016). "Speed Control of DC Motor using Chopper (MATLAB Simulation)". (Vol. 3) International Journal on Recent Technologies in Mechanical and Electrical Engineering (IJRMEE).

[15] Nagarajan, D. R., Sathishkumar, S., Balasubramani, K., Boobalan, C., Naveen, S., \& Sridhar, N. (2016). "Chopper Fed Speed Control of DC Motor Using PI Controller. IOSR-Journal of Electrical and Electronics Engineering (IOSR-JEEE), 11(3), 65-69.

[16] Kanai, M. M., Nderu, J. N., \& Hinga, P. K. (2011). “Adaptive PID DC motor speed controller with parameters optimized with hybrid optimization strategy." In Second International Conference on Advances in Engineering and Technology, pp. 121-127.

[17] Chen, C. (2015). "Self-tuning PID Control of Induction Motor Speed Control System Based on Diagonal Recurrent Neural Network." International Journal of Control and Automation, 8(10), 321-334.

[18] Zhu, L. (2008). "Adaptive control of sinusoidal brushless DC motor actuators." Michigan Technological University.

[19] Sahputro, S. D., Fadilah, F., Wicaksono, N. A., \& Yusivar, F. (2017, July). "Design and implementation of adaptive PID controller for speed control of DC motor". In Quality in Research (QiR): International Symposium on Electrical and Computer Engineering, 2017 15th International Conference on, pp. 179-183. IEEE.

\section{BIOGRAPHIES OF AUTHORS}

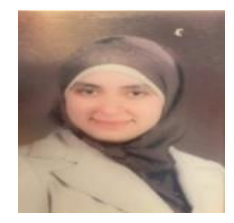

Sarah Nabhan Al-Bargothi received the B.Eng. degree from The Hashemite University, Zarqa, Jordan, in 2009, and the M.Sc. degree from Al-Balqa Applied University, Salt, Jordan, in 2018. She is currently a laboratory supervisor in the Department of Mechatronics Engineering, Faculty of Engineering, Hashemite University. Email: Sarahb_eng@yahoo.com

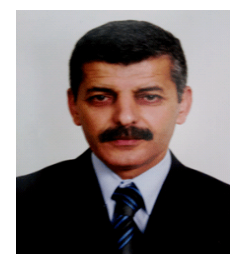

Ghazi M. Qaryouti received his B.Sc. in electrical Engineering from Damascus university in 1982, and M.S in Mechatronics Engineering from Al-Balqa' Applied University Jordan in 2006, and Ph.D. degrees in Mechatronics Engineering from De Montfort University in Leicester, UK in 2015 His research interests are in Power Electronics and Electric Machine Drives, CNC Machine, 3D Printer, Energy Efficiency and Management, and Renewable System.

Email : ghazi_qaryouti@bau.edu.jo

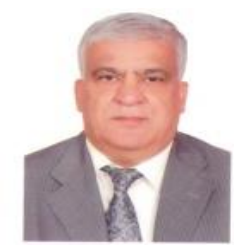

Qazem Jaber received his M.S. and Ph.D. degrees in Electrical Drive and Automation Engineering from Moscow Power Institute in 1982 and 1986 respectively. Currently Dr. Qazem Jaber an Professor at Department of Mechatronics Engineering, Al-Balqa' Applied University Jordan. His research interests are in Power Electronics and Electric Drives, Energy Efficiency and Management, and Renewable System. Email : qazimjaber@bau.edu.jo 